\title{
PREDATOR EFFECTS ON AN ASSEMBLAGE OF CONSUMERS THROUGH INDUCED CHANGES IN CONSUMER FORAGING BEHAVIOR
}

\author{
Scott D. Peacor And EArl E. Werner \\ Department of Biology, University of Michigan, Ann Arbor, Michigan 48109 USA
}

\begin{abstract}
This investigation examines how a predator-induced reduction in activity of a prey species (a "nonlethal" predator effect) affects the growth rate of the prey and, indirectly, the growth rate of competitors of the prey. We further determine how the magnitudes of these effects depend on density of the prey species. We develop a foraging model that predicts a predator will reduce the growth of a focal prey species at low prey density but have little effect at high prey density. The model also predicts that presence of the predator will indirectly facilitate growth of a competitor of the focal species, and that this effect will be negligible at low, and maximal at high, focal species density. Thus it is precisely where the effect of the predator on the growth of the focal species is minimum that the indirect effect on the competitor is maximum.

We tested these predictions using a system of three species/size classes of anuran larvae and a larval odonate predator (Anax longipes) in cattle watering tanks. By caging the predator we isolated its effect on foraging behavior of the anuran larvae from that of density reduction. We manipulated the density of small green frog larvae (Rana clamitans) while holding density of small bullfrog ( $R$. catesbeiana) and large green frog competitors constant. Small green frogs and bullfrogs reduce their activity in the presence of caged Anax whereas the large green frogs do not.

Results were in accord with the model predictions. Caged Anax reduced small green frog and bullfrog growth at low small green frog density but had no effect at high small green frog density. In contrast, caged Anax had a positive effect on large green frog growth, but this effect was negligible at low small green frog density and maximal at high small green frog density. The results also showed that the indirect effects of the predator that arose through reduction in prey foraging activity were comparable in magnitude to those expected through reduction in prey density. These results suggest that the nonlethal effects of a predator on prey and, indirectly, on competitors of their prey, can be large in magnitude and depend strongly on relative species densities.
\end{abstract}

Key words: Anax; anuran larvae; behavioral induction; density-dependence; density-mediated indirect interaction; odonate; predation risk; Rana; trait-mediated indirect interaction.

\section{INTRODUCTION}

A community of interacting species may be conceptualized as a food web where species are linked by their direct consumer-resource interactions. Thus, a species may directly or indirectly affect other species in the community via these links (reviewed in Schoener 1993, Menge 1994, Polis and Winemiller 1996). The magnitude of the direct interaction link between the consumer and resource, or the interaction coefficient, is typically modeled in ecological theory as a constant or as a function of the density of the two species. A fundamental question is whether this interaction coefficient is dependent on other species in the food web as well; i.e., are there higher-order interactions (Vandermeer 1969, Roughgarden and Diamond 1986, Wootton 1993)? There has been a long-standing concern over whether such higher-order interactions are of sufficient magnitude to affect community dynamics (Vandermeer 1969, 1981, Neill 1974, Pomerantz 1981,

Manuscript received 27 August 1998; revised 2 March 1999; accepted 4 June 1999; final version received 25 June 1999.
Abrams 1983, Wilbur and Fauth 1990), and renewed interest is reflected in a recent Special Feature in Ecology (Adler and Morris 1994, Billick and Case 1994, Wootton 1994). If higher-order interactions are important, interaction coefficients estimated from two-species experiments are of limited value in predicting species interactions under different conditions.

One of several processes that can lead to higher-order interactions is phenotypic plasticity in species traits (e.g., behavior, morphology, or life history). If one species affects a phenotypically plastic trait of a second species, then the interactions of the second species with a third species in the system may be altered. This means that a species can have an indirect effect on another through changes in a trait, rather than the density, of an intermediate species. Such indirect interactions have been termed trait-mediated indirect interactions (TMIIs, Abrams et. al 1996; also behavioral indirect interactions, Miller and Kerfoot 1987; interaction-modifications, Wootton 1993), in contrast to density-mediated indirect interactions that involve changes in the density of the intermediate species (Abrams et. al 
1996). TMIIs represent a type of higher-order interaction because the coefficient describing the interaction between two species (in this case the second and third species) is dependent on the density of another species (in this case the first species); i.e., the per capita effect of the second species on the third species is a function of the density of the first species.

We suspect that TMIIs are widespread in many food webs and that their importance has been underestimated (Miller and Kerfoot 1987, Werner 1992, Wootton 1993). An extensive literature documents phenotypic responses in many species that could result in TMIIs, especially in the case of predator-induced changes in prey behavior (e.g., Lima and Dill 1990, Lima 1998). Further, recent studies in both aquatic (Soluk and Collins 1988, Huang and Sih 1990, Turner and Mittlebach 1990, Werner 1991, Wissinger and McGrady 1993, Wootton 1993, 1997, Skelly 1995, McIntosh and Townsend 1996, Werner and Anholt 1996, Peacor and Werner 1997) and terrestrial (Messina 1981, Beckerman et al. 1997, Schmitz et al. 1997; J. M. Scanio, unpublished manuscript) systems have demonstrated that TMIIs generated by these responses can be quantitatively important.

The characteristics of a food web that will influence the expression of TMIIs have been little explored in this literature. For example, investigators typically have manipulated presence and absence of a predator at constant prey densities to demonstrate the existence of TMIIs (but see Soluk 1993, Werner and Anholt 1996, Kratz 1996). However, a study by Werner and Anholt (1996) suggests that the TMII induced by a predator can be strongly dependent on the density of the intermediate species. Since relative species densities vary across food webs, and temporally and spatially in a given system, we must understand the relationship between species densities and TMIIs to predict their consequences to food web structure.

In this investigation, we show how a predator-induced reduction in foraging activity of a focal prey species affects the growth rate of both the focal prey species and its competitors at different densities of the focal prey species. The changes in competitor growth rates represent a TMII, i.e., the predator affects the growth rate of the competitors indirectly via changes in a trait (in this case foraging behavior) of the focal prey species. We first generate several predictions using a simple foraging model. We then test these predictions experimentally using an aquatic food web consisting of the larvae of several anuran species/size classes and a larval odonate predator. In both the model and the experiment we examine the effects of the predator-induced reduction in foraging activity of the prey isolated from any reduction in density (consumption of prey). By isolating the effects of the trait changes, we can better examine and illustrate the mechanisms involved in TMIIs. Furthermore, in the experiment, treatments with different relative initial densities of competitors

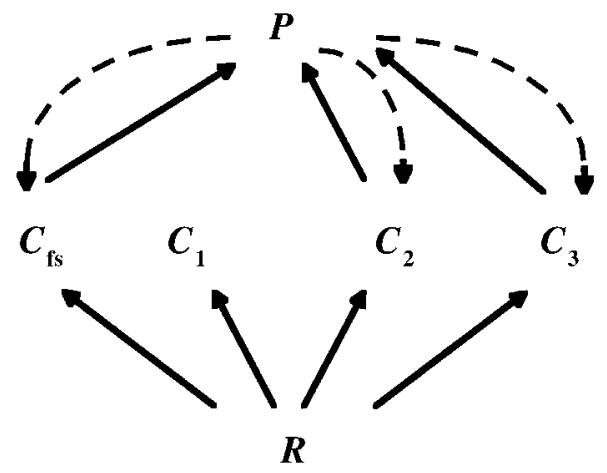

FIG. 1. The model food web composed of one predator species $(P)$, a focal species consumer $\left(C_{\mathrm{fs}}\right)$, three competitors of the focal species, and a resource $(R)$. The predator induces a reduction in the foraging activity of $C_{\mathrm{fs}}$ (represented by the curved arrow). $C_{1}$, which is invulnerable to the predator, does not react to the predator, while $C_{2}$ and $C_{3}$ reduce their foraging activity in the presence of the predator by either the same amount as $C_{\mathrm{fs}}\left(C_{2}\right)$ or more than $C_{\mathrm{fs}}\left(C_{3}\right)$. In the experimental food web, $C_{\mathrm{fs}}, C_{1}$, and $C_{2}$ are represented by small green frog, large green frog, and bullfrog tadpoles, respectively.

allow us to examine the combined effects of a predator on prey traits and prey density.

\section{Predictions}

We use a simple model to examine how a predatorinduced reduction in the foraging activity of a focal consumer affects an assemblage of consumers (Fig. 1). In any community, competitors of a focal species may react differentially to the presence of a predator; some will reduce their foraging effort, while others may be invulnerable to the predator and not react at all. By choosing competitors that react to the presence of the predator, less strongly $\left(C_{1}\right)$, the same $\left(C_{2}\right)$, and more strongly $\left(C_{3}\right)$ than the focal species $\left(C_{\mathrm{fs}}\right)$, we can examine a broad range of potential consequences of the presence of a predator to competitive interactions. We examine these consequences at different densities of the focal species while keeping competitor densities low, thus asking how the induced reduction in foraging activity of the focal species will affect the community in the absence of reciprocal effects from the competitors. While the effects of the predator will still operate when reciprocal effects are considerable, examining a system in which they are negligible helps to clarify the effects of the predator and the mechanisms which underlie the effects. Note that we are examining only the nonlethal effects of a predator (i.e., there is no mortality due to predation on consumers). Thus the effects of the predator are restricted to consequences of the predatorinduced foraging reduction.

We assume that the growth rate of an individual consumer is proportional to the fraction of the total resources, $f$, that it acquires in a finite period of time. Two factors will affect $f$ : the foraging ability of the individual and the level of competition for resources. We represent the foraging ability of an individual by 
the fraction of resources, $f^{\prime}$, it would acquire if isolated from any competitors (intraspecific and interspecific). Thus $f^{\prime}$ is proportional to the fraction of the resource space that is foraged and can be thought of as the foraging effort of the consumer (Abrams 1993). For example, $f^{\prime}$ may represent the area that a surface grazer forages in a finite period of time. Thus, in the absence of any competition, the fraction of resources acquired is equal to the fraction of the surface grazed, i.e., $f=$ $f^{\prime}$. However, in the presence of competitors the fraction of resources acquired is less than the fraction of surface grazed, i.e., $f<f^{\prime}$. Similar arguments could be applied to other types of consumers, such as filter feeders, where $f^{\prime}$ represents the fraction of water filtered, or for predators, where $f^{\prime}$ may represent the fraction of potential prey sites the predator searches.

Now we ask, how will a predator affect $f$ ? Consider the case of $C_{2}$ in Fig. 1. The predator will have a negative effect on the foraging activity of $C_{2}$, which will clearly have a negative effect on the fraction of resources, $f_{2}$, that $C_{2}$ acquires. However, the predatorinduced foraging reduction of $C_{\mathrm{fs}}$ will have an indirect positive effect on $f_{2}$ by reducing the rate that $C_{\mathrm{fs}}$ removes resources from the system. This indirect effect represents a TMII of the predator on $C_{2}$ through changes in the foraging activity of $C_{\mathrm{fs}}$. We will see that these opposing nonlethal effects of the predator are strongly dependent on $C_{\mathrm{fs}}$ density. We are interested in the net relative effects of the predator as a function of $C_{\mathrm{fs}}$ density, i.e., the magnitude of the effect of the predator is the percent change in growth rate of the consumer in the presence of the predator, not the absolute change. We thus discuss the nonlethal effects of the predator in terms of the ratio of $f$ with and without the predator.

First we consider the effect of foraging reduction on $C_{\mathrm{fs}}$ as a function of $C_{\mathrm{fs}}$ density. If we assume that consumers forage randomly, then the total fraction of resources acquired by the $C_{\mathrm{fs}}$ population, $F_{\mathrm{fs}}$, in a given time interval will be

$$
F_{\mathrm{fs}}=1-\left(1-f_{\mathrm{fs}}^{\prime}\right)^{n_{\mathrm{fs}}}
$$

where $n_{\mathrm{fs}}$ is the number of focal species individuals. The fraction of resources an individual $C_{\mathrm{fs}}$ will acquire $\left(f_{\mathrm{fs}}\right)$ is then

$$
f_{\mathrm{fs}}=\frac{1}{n_{\mathrm{fs}}}\left[1-\left(1-f_{\mathrm{fs}}\right)^{n_{\mathrm{fs}}}\right] .
$$

It follows from Eq. 2 that at higher densities an individual consumer acquires a smaller fraction of the resources as expected when there is intraspecific competition (Fig. 2a).

We can now use Eq. 2 to compute $f_{\mathrm{fs}}$ with a predatorinduced foraging reduction. We assume that the reduction in $f_{\mathrm{fs}}^{\prime}$ is equal to the predator-induced foraging reduction, e.g., in the absence of competition, if an isolated individual consumer is $40 \%$ less active due to the predator-induced foraging reduction, $f_{\mathrm{fs}}^{\prime}$ will be re-

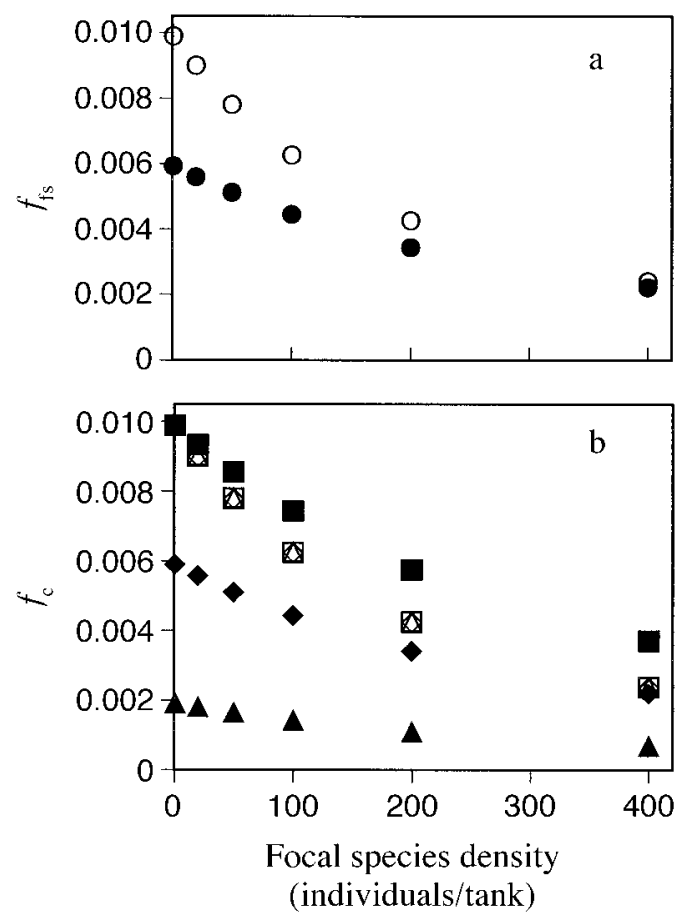

FIG. 2. Model results. (a) The fraction of resources acquired by a focal species individual $\left(f_{\mathrm{fs}}\right)$ as a function of focal species density $\left(n_{\mathrm{fs}}\right)$ without (open circles) and with (closed circles) a predator-induced foraging reduction of $40 \%$. An isolated individual is assumed to acquire $1 \%$ of the resources when alone $\left(f_{\mathrm{fs}}^{\prime}=0.01\right)$. The predator has a strong negative effect on $f_{\mathrm{fs}}$ at low density, but little effect at high density. (b) The fraction of resources acquired by an individual of each competitor species $\left(f_{\mathrm{c}}\right)$ as a function of focal species density. Each species forages identically to the focal species in the absence of predation risk, and thus each species gains the same fraction of resources as the focal species in the absence of the predator (open symbols). (Note that equal foraging in the absence of predation risk was chosen only to make presentation of the model results more clear and has no bearing on the predictions of the model.) Presence of the predator has a positive effect on the fraction of resources acquired by $C_{1}$ (closed squares), which does not react to the predator, and a negative effect on $C_{2}$ (closed diamonds) and $C_{3}$ (closed triangles), which reduce their foraging activity the same and twice as much as $C_{\mathrm{fs}}$, respectively. The positive effect of the predator on $C_{1}$ is largest at high focal species density, while the negative effect on $C_{2}$ and $C_{3}$ is largest at low focal species densities.

duced by $40 \%$. The actual fraction of resources obtained, $f_{\mathrm{fs}}$, with a predator-induced foraging reduction of $40 \%$ at different densities of $C_{\mathrm{fs}}$ is illustrated in Fig. $2 \mathrm{a}$. As in the absence of the predator, $f_{\mathrm{fs}}$ is lower at higher consumer density due to intraspecific competition. The relative effect of the predator-induced foraging reduction, however, is strongly dependent on focal species density; at low density there is a strong negative effect on $f_{\mathrm{fs}}$, while at high density the effect is negligible. The result at low density is intuitive: the reduction in foraging has a direct negative effect on the amount of resources an individual can acquire. At 
TABLE 1. The predicted nonlethal effect of the predator on the growth of the consumers depicted in Fig. 1 at low and high focal species $\left(C_{\mathrm{fs}}\right)$ density.

\begin{tabular}{llllll}
\hline \hline \multirow{2}{*}{ Effect } & \multirow{2}{*}{$C_{\mathrm{fs}}$} & \multicolumn{4}{c}{ Nonlethal effect of predator on species: } \\
\cline { 3 - 6 } & density & \multicolumn{1}{c}{$C_{\mathrm{fs}}$} & \multicolumn{1}{c}{$C_{1}$} & \multicolumn{1}{c}{$C_{2}$} & \multicolumn{1}{c}{$C_{3}$} \\
\hline Foraging reduction & low & large(-) & absent & large(-) & large(-) \\
& high & large(-) & absent & large(-) & large(-) \\
Indirect effect & low & small & small & small & small \\
& high & large(+) & large(+) & large(+) & large(+) \\
Net effect & low & large(-) & small & large(-) & large(-) \\
& high & small & large(+) & small & large(-) \\
\hline
\end{tabular}

Notes: The net effect on consumer growth results from the relative magnitudes of the predatorinduced foraging reduction of the consumer and an indirect effect on resources (the TMII) through the predator-induced foraging reduction of competitors of the consumer (intraspecific and interspecific). The signs of the effects are in parentheses. The relative densities and activity levels of the competitors are as described in the text.

high density, however, there is a positive effect that offsets the negative effect. By reducing the foraging activity of the assemblage of consumers, the predator has an indirect positive effect on the amount of resources available to an individual consumer. Thus, the reduction in the amount of resources acquired by an individual, $f_{\mathrm{fs}}$, is less than the reduction in the foraging effort, $f_{\mathrm{fs}}^{\prime}$. At low density this positive indirect effect of the predator on the individual consumer is negligible because there is little pressure on resources and hence no competition. At very high consumer densities the positive indirect effect counterbalances the negative effect of the predator on foraging activity (Fig. 2a). We thus predict that the predator-induced foraging reduction will have a strong negative effect on individual $C_{\mathrm{fs}}$ growth rates at low $C_{\mathrm{fs}}$ density and no net effect at high $C_{\mathrm{fs}}$ density (Table 1 ).

The counterintuitive result at high $C_{\mathrm{fs}}$ density is easily illustrated with an example. Consider an extreme case in which an individual consumer in the absence of conspecifics acquires a large percentage of the resources, say $10 \%\left(f_{\mathrm{fs}}=f_{\mathrm{fs}}^{\prime}=0.1\right)$, in a finite time period. If a predator induces a $50 \%$ reduction in foraging activity, the same individual consumer will acquire only $5 \%$ of the resources. Using Eq. 2, we find that in a system with high densities (say 100) of such consumers each individual will acquire $1.0 \%$ and $0.994 \%$ of the resources with and without the $50 \%$ foraging reduction, respectively. Thus the negative effect of the predator is much weeker at high density $\left(\sim 0.6 \%\right.$ reduction in $\left.f^{\prime}\right)$ than at low density $(\sim 50 \%$ reduction in $\left.f^{\prime}\right)$. Note that while there is a negligible net effect of the predator on the individual consumer at high density, this is due to the opposing negative and positive effects.

Now consider competitors (e.g., $C_{1}, C_{2}$, and $C_{3}$; Fig. 1) of the focal species. If we again assume random foraging, the fraction of resources acquired by an individual competitor $f_{\mathrm{c}}$ in a finite time period is

$$
f_{c}=\frac{1}{n_{c}}\left(\frac{n_{c} f_{c}^{\prime}}{n_{\mathrm{fs}} f_{\mathrm{fs}}^{\prime}+n_{c} f_{c}^{\prime}}\right)\left[1-\left(1-f_{\mathrm{fs}}^{\prime}\right)^{n_{\mathrm{fs}}}\left(1-f_{c}^{\prime}\right)^{n_{c}}\right]
$$

where $n_{\mathrm{c}}$ is the number of individuals of the competitor species and $f_{c}^{\prime}$ is the fraction of resources acquired by an isolated individual competitor. The second bracketed term is the total amount of resources acquired by both species, and the first bracketed term is the proportion of these resources gained by the competitor species. Using Eq. 3, we can examine how a predatorinduced reduction in foraging activity of the focal species and of the competitor species will affect the amount of resources acquired by an individual competitor, $f_{c}$, as a function of the focal species density, $n_{\mathrm{fs}}$.

The nonlethal effect of the predator is strongly dependent on focal species density. At low $n_{\mathrm{fs}}$ Eq. 3 reduces to

$$
\lim _{n_{\mathrm{ss}} \rightarrow 0} f_{c}=f_{c}^{\prime} .
$$

As expected, in the absence of competition from the focal species, the effect of the predator on $f_{\mathrm{c}}$ is equal to the effect of the predator on $f_{c}^{\prime}$; i.e., any reduction in foraging effort has an equivalent negative effect on resources acquired. At high focal species density, however, $f_{\mathrm{c}}$ will be lower than $f_{c}^{\prime}$ due to competition from $C_{\mathrm{fs}}$. This is represented by Eq. 3 which at high $C_{\mathrm{fs}}$ density reduces to

$$
\lim _{n_{\mathrm{fs}} \rightarrow \infty} f_{c}=\frac{f_{c}^{\prime}}{n_{\mathrm{fs}} f_{\mathrm{fs}}^{\prime}} .
$$

Thus, at high $n_{\mathrm{fs}}, f_{\mathrm{c}}$ is proportional to the ratio of the rates that the competitor and the focal species acquire resources. Intuitively, at high focal species density, resources are limited and the fraction of resources an individual consumer acquires will be directly proportional to the rate at which it forages and inversely proportional to the rate at which a dominant competitor (in this case the focal species) removes the resources. If a predator has a differential effect on the foraging activity of the focal species and the competitor, then the predator will affect $f_{\mathrm{c}}$. We use the coefficient $\Delta$ to represent the reduction in the fraction of resources ac- 
quired by a single individual in isolation. Thus an isolated individual acquires $f_{c}^{\prime}$ and $f_{c}^{\prime} \times(1-\Delta)$ in the presence and absence of the predator, respectively. Using Eq. 5 we see that the ratio of the amount of resources gained by the competitor with and without the predator at high focal species density is

$$
\frac{f_{c}(\mathrm{w} / \text { pred })}{f_{c}(\text { no pred })}=\frac{1-\Delta_{c}}{1-\Delta_{\mathrm{fs}}}
$$

That is, the effect of the predator on competitor growth at high focal species density is equal to the ratio of 1 minus the predator-induced reduction in foraging effort of the competitor and the focal species.

We now can examine the effect of the predator-induced foraging reduction on the different competitors. To represent consumers that react to the predator less, the same, and more than the focal species, we let $\Delta_{\mathrm{fs}}$, $\Delta_{1}, \Delta_{2}$, and $\Delta_{3}$ be $X, 0, X$, and $2 X$, respectively. For simplicity, we assume that in the absence of the predator the competitors acquire the same amount of resources as $C_{\mathrm{fs}}$. At low focal species density (no competition) the effect of the nonlethal predator is directly proportional to the competitor's response to the predator (Fig. 2b). Hence the predator does not affect the amount of resources acquired by $C_{1}$, and reduces the amount of resources acquired by $C_{2}$ and $C_{3}$ by $X$ and $2 X$, respectively. At high focal species density, in contrast, the focal species will affect the amount of resources acquired by the competitors, and the net effect of the predator is determined by Eq. 6 . Thus the predator will lead to an increase in the growth rate of the $C_{1}$ by $1 /(1-X)$, will have no effect on the amount of resources acquired by $C_{2}$, and lead to a decrease in the amount of resources acquired by $C_{3}$ by $(1-2 X) /(1-$ $X)$. These results are summarized in Table 1 .

The nonlethal effects of the predator on competitor growth rates are due to the same two mechanisms that operate on the focal species growth rate. At low focal species density, there is a negative effect of the predator on growth proportional to the reduction in individual consumer activity. At higher focal species density the aggregate reduction in the focal species foraging activity leads to a positive indirect effect on the amount of resources available (a TMII). The net nonlethal effect of the predator incorporates both the negative and positive effects and is a function of focal species density. For $C_{1}$, which does not react to the predator, the positive indirect effect dominates at high $n_{\mathrm{fs}}$ and thus there is a net positive effect of the predator on $C_{1}$ growth rate. For $C_{2}$, which reacts to the predator the same amount as the focal species, the negative and the indirect positive effects are equal in magnitude, and there is thus no net effect of the predator. Finally, for $C_{3}$, which reacts more strongly to the predator, the negative effect is stronger than the positive indirect effect and thus there is a net negative effect of the predator.

From this model, we can make the following pre- dictions. (1) Although the predator will affect the foraging effort of $C_{\mathrm{fs}}$ individuals at all densities, the nonlethal effect on the growth rate of $C_{\mathrm{fs}}$ will be substantial and negative at low $C_{\mathrm{fs}}$ density, and negligible at high $C_{\mathrm{fs}}$ density. (2) The predator will facilitate the growth rate of a competitor, $C_{1}$, (that does not react to the presence of the predator) at high $C_{\mathrm{fs}}$ density, but will have little effect at low $C_{\mathrm{fs}}$ density. (3) The predator will depress the growth rate of a competitor, $C_{2}$, (that reduces its foraging effort in the presence of the predator by a similar proportion as $C_{\mathrm{fs}}$ ) at low $C_{\mathrm{fs}}$ density, but not at high $C_{\mathrm{fs}}$ density. (4) The predator will depress the growth rate of a competitor, $C_{3}$, (that reduces its foraging effort in the presence of the predator proportionately more than $C_{\mathrm{fs}}$ ) at all $C_{\mathrm{fs}}$ densities, and the relative magnitude of the reduction will be greater at low $C_{\mathrm{fs}}$ density.

\section{Methods}

\section{Cattle tank experiment}

We conducted an experiment testing the predictions of the model using an aquatic food web consisting of a caged (nonlethal) larval dragonfly predator (Anax longipes) and three species/size classes of larval anuran consumers. Small green frogs (Rana clamitans) were the focal consumer species, small bullfrogs ( $R$. catesbeiana) and large second-year green frogs were the competitors. Larval anurans can sense the presence of Anax via chemical cues. By caging the predator we were able to investigate nonlethal effects of the predator in the absence of any effects due to density reduction of the larval anurans (Kats et al. 1988, Werner 1991, McCollum and VanBuskirk 1996). Small green frogs reduce their activity in the presence of caged Anax (Werner 1991, Peacor and Werner 1997). Small bullfrogs, which are more active than small green frog tadpoles, reduce their activity in the presence of Anax by approximately the same proportion as small green frogs (Werner 1991). Large second year green frog larvae $(\sim 1 \mathrm{~g})$, on the other hand, are much less vulnerable to Anax predation and react less strongly to the presence of caged Anax. Thus the small green frogs, large green frogs and small bullfrogs are represented by $C_{\mathrm{fs}}$, $C_{1}$, and $C_{2}$ in the model predictions (Table 1, Fig. 1). There was no species in the system that reacts more strongly than small green frogs to caged Anax, and hence we tested model predictions for $C_{\mathrm{fs}}, C_{1}$, and $C_{2}$ only.

The study was performed at the University of Michigan's E. S. George Reserve experimental pond site in southern Michigan. Experiments were conducted in cylindrical cattle watering tanks $1.9 \mathrm{~m}$ in diameter $\times 0.75$ $\mathrm{m}$ tall. Tanks were filled with $1300 \mathrm{~L}$ of well water and covered with fiberglass window screening to deter oviposition and colonization by aquatic insects. Each tank received four small cylindrical predator cages $(11 \mathrm{~cm}$ in diameter $\times 10.5 \mathrm{~cm}$ in length) constructed from 
slotted plastic drainpipe with ends enclosed by fiberglass window screening. A small piece of polystyrene was placed in the cage to ensure that the cages floated near the surface. Each tank received $300 \mathrm{~g}$ of dry oak leaves (Quercus sp.) as a substrate for resources and to add physical complexity. Each tank was inoculated with phytoplankton, periphyton, and zooplankton collected from a local pond. The tadpoles used in this experiment feed primarily on periphyton by scraping the surfaces of tank walls and leaves. To provide nutrients for periphyton growth, we added $0.967 \mathrm{mmol} /$ $\mathrm{m}^{3}$ of $\mathrm{N}$, in the form of $\mathrm{NH}_{4} \mathrm{NO}_{3}$, and $0.076 \mathrm{mmol} / \mathrm{m}^{3}$ of $\mathrm{P}$, in the form of $\mathrm{KH}_{2} \mathrm{PO}_{4}$, to each tank daily. This represented a $13 \mathrm{~N}: 1 \mathrm{P}$ molar ratio. This procedure leads to a moderate $(\sim 50 \%)$ increase in tadpole biomass gain (S. D. Peacor, unpublished data).

We employed a $2 \times 6$ factorial design, in which caged Anax/no Anax treatments were crossed with six small green frog densities; 0, 40, 80, 160, 240, and 320 tadpoles per tank (mean mass of $17.6 \pm 5.7 \mathrm{mg}$ ). Past experiments indicate that there is significant competition at the high densities used and hence this range encompassed that used in the model to make our predictions. By using a range of densities we were also able to compare effects due to foraging reduction and density reduction. As competitors, each tank also received 15 small bullfrog tadpoles $(18.2 \pm 4.0 \mathrm{mg}$ [mean $\pm 1 \mathrm{SE}])$ and 5 large green frog tadpoles $(1.64 \pm 0.35$ g). We selected the density of each competitor to minimize reciprocal competitive effects. Because small bullfrog tadpoles have a weaker effect on resources than large green frog tadpoles we were able to use more small bullfrog tadpoles. The initial total mass of the large green frogs was measured for each tank. The average masses of the small bullfrogs and green frogs were determined by weighing 60 haphazardly chosen tadpoles from the populations used. The 12 treatments were replicated four times in four spatial blocks. (Four small gray tree frogs [Hyla versicolor, $7.6 \pm 0.3 \mathrm{mg}$ ] also were added to each tank and were originally intended as a third competitor. However, the gray tree frogs used different resources [in the water column], survivorship was very low in some tanks, and a high number metamorphosed during the experiment. We thus did not use their growth rate as a response.)

Small tadpoles were obtained from cultures initiated with several egg masses collected from the E. S. George Reserve experimental ponds (green frogs), or the Michigan DNR ponds near Saline, Michigan (bullfrogs). The eggs were transferred to wading pools filled with well water and, after hatching, tadpoles were fed Purina rabbit chow (Ralston Purina, St. Louis, Missouri, USA). Large overwintering green frog tadpoles were collected from three of the experimental ponds. The large green frogs, small bullfrogs, and small green frogs were added to the tanks on 26 June, 26 June, and 27 June 1995 respectively. At this time, $\sim 10 \mathrm{~d}$ after the tank environments were prepared, there was a uniform layer of periphyton on the tank walls and leaf surfaces. On 29 June one Anax (final instar) was added to each of the four cages in the caged Anax treatment tanks. Anax were fed six small green frog tadpoles (mean individual mass $=40 \mathrm{mg}$ ) as a food source three times weekly, and they were replaced if they did not eat. Feeding the Anax magnifies the chemical cue that induces the reduction in tadpole foraging (S. A. McCollum, personal communication).

Tadpoles generally react to predators by reducing activity and spending more time on the substrate (Sih 1987, Lawler 1989, Skelly and Werner 1990, Semlitsch 1993, Smith and VanBuskirk 1995, Peacor and Werner 1997). On 17 July we estimated tadpole foraging effort by counting the number of small tadpoles that were not on the tank bottom but were either in the water column or on the tank sides. We could not use percent active as a response because the number of visible tadpoles in the caged Anax treatments was often zero. We conducted these observations three times at 2-h intervals and a mean value was computed for each tank. To normalize the response across densities, we calculated the percent of tadpoles above the tank bottom by dividing the number counted by the number of survivors (determined 1-3 d later).

On 18-20 July, three weeks after the experiment began, leaves were removed from the tanks by hand and the tadpoles were collected with dipnets. The tanks were then drained, and any remaining tadpoles collected. The tadpoles were immediately sorted by species, counted, and weighed.

Survivorship was first analyzed to determine whether it confounded growth responses. The small green frog density, nonlethal (caged) Anax presence, and the interaction between these variables on the survival of the small green frog and bullfrog tadpoles was analyzed using ANCOVA. Preliminary analysis indicated that there were no block effects and thus block was not included in the ANCOVA. The zero green frog density treatment precluded the possibility of using MANCOVA. Survivorship was arcsine square-root transformed (to satisfy the assumption of normality) and the initial small green frog density was the covariate. Survivorship of large green frogs was $100 \%$ in all but a few tanks and thus no statistical analysis was necessary.

We used MANCOVA to test whether block, small green frog density, nonlethal (caged) Anax presence, and the interaction between these treatments affected bullfrog and large green frog mass gain (mass gain was used as a measure of growth rate). The initial small green frog density was the covariate. Since there was a zero small green frog density treatment, we did not include small green frog mass gain in the MANCOVA. We used ANCOVA to examine treatment effects on the mass gain of the three species/size classes separately. Lilliefors test was used to assure that the residuals of the log-transformed data did not deviate significantly from normality. 
Our primary prediction requires that a significant interaction term occur between small green frog density and nonlethal Anax presence. Since transforming data can have a strong influence on the significance of interaction terms (Billick and Case 1994, Wootton 1994), it was necessary to carefully choose the proper transformation for mass gain. We were interested in the relative effect of the predator on mass gain at different small green frog densities. In other words, we compared the percent change in mass gain of anuran larvae caused by caged Anax at low and high densities of small green frogs. Log transformation of mass gain ensured that a significant interaction between caged Anax presence and small green frog density indicated that the relative effect of the caged Anax on tadpole mass gain was dependent on small green frog density.

By using small green frog density as a covariate in our statistical analyses, we implicitly tested a linear relationship between small green frog density and mass gain. The experimental results and model predictions (Fig. 2), however, suggested that mass gain falls more steeply as a function of small green frog density. We thus also analyzed our data using the square root of small green frog density as a covariate. This analysis yields an identical interpretation of the experimental results. We present results using the untransformed density since our predictions did not consider the functional form of the small green frog density on mass gain.

The effect of small green frog density on small green frog and bullfrog position in the tank was analyzed with the Kruskal-Wallis nonparametric test, because there were many treatments with no variance between replicates. The effect of the caged Anax on position was so obvious, resulting in many zero observations, that we include no statistical analysis.

\section{Laboratory experiment on nonlethal predator effects}

An additional experiment was performed in the laboratory to compare the activity responses of large and small green frog tadpole size classes to caged Anax. The experimental units were 40-L aquaria filled with well water. Each tank received 15 small green frogs $(30.8 \pm 6.9 \mathrm{mg})$ or 10 large green frogs $(2.84 \pm 0.38$ g) which were collected and reared in the same manner and from the same sources as for the cattle tank experiment. Masses were attained by weighing tadpoles from the same cultures used in the experiment. Tadpoles were fed $3 \%$ of body mass of a finely ground 3 : 1 mixture of rabbit chow and Tetramin Fish Flakes (Tetra, Morris Plains, New Jersey, USA) the day before observations were made. One small predator cage, constructed from mosquito netting, was suspended in each tank. We used a $2 \times 2$ factorial design with six blocks separated spatially. Treatments included the two tadpole size classes crossed with the presence and absence of caged Anax. Anax were placed in the cages with three small green frog tadpoles (mean mass $110 \mathrm{mg}$ )
$1 \mathrm{~d}$ after the introduction of the tadpoles. Observations were initiated $3 \mathrm{~h}$ after the addition of the Anax. Two responses were recorded every $15 \min$ for $4 \mathrm{~h}$ : (1) the number of tadpoles active (feeding or swimming), and (2) the number of tadpoles above the tank bottom.

\section{RESUlts}

\section{Survivorship}

Survivorship was high for all species; $85 \%, 78 \%$, and $97 \%$ of the small green frogs, bullfrogs, and large green frogs survived, respectively. Results of the ANCOVA showed that caged Anax did not affect survivorship of the small green frogs $(P=0.6)$ or bullfrogs $(P=0.8)$. Small green frog density had a small negative effect on the survivorship of small green frogs $(\sim 8 \%, P=0.0016)$ and bullfrogs $(\sim 10 \%, P=0.041)$. The effect of the interaction of caged Anax presence and small green frog density was insignificant for both small green frogs and bullfrogs $(P=0.58$ and 0.49 for small green frogs and bullfrogs, respectively). These results indicate that survivorship did not confound the effects of density and caged Anax presence on tadpole mass gains.

\section{Mass gain}

Large green frog individuals gained approximately four times as much mass as bullfrogs, which gained approximately twice as much mass as small green frogs. The mean mass gain of all three species/size classes decreased with an increase in small green frog density (Table 2, Fig. 3). MANCOVA indicated that caged Anax, small green frog density, and the interaction between these variables had a significant effect on tadpole mass gain (Table 2). There was also a significant small green frog density by block interaction.

ANCOVAs indicated that the interaction between the predator and small green frog density was significant for all three species/size classes (Table 2). This is because the relative effect of the predator differed at different small green frog densities. For small green frogs and bullfrogs the predator had a negative effect on mass gain that was much stronger at low than at high small green frog density. This negative effect decreased from $\sim 40-50 \%$ to $0 \%$ for small green frogs and bullfrogs (Fig. $3 \mathrm{a}$ and $3 \mathrm{~b}$ ). In contrast, the predator had a positive effect on large green frog mass gain that was relatively stronger at high than at low small green frog density. This positive effect increased from approximately $10 \%$ to $60 \%$ as small green frog density increased from 0 to 320 (Fig. 3c).

\section{Observations}

Most small tadpoles were not visible and presumably taking refuge under the oak leaves during observations. Tadpoles observed above the tank floor were almost exclusively resting on, or active near, the tank sides. The percentage of small green frogs and bullfrogs seen 
TABLE 2. Results of MANCOVA for the effects of small green frog density, caged Anax, and block on the mass gain of large green frogs and bullfrogs and univariate responses to small green frog density, caged Anax, and block of large green frogs, bullfrogs, and small green frogs.

\begin{tabular}{|c|c|c|c|c|c|c|c|c|c|c|c|}
\hline \multirow[b]{3}{*}{ Source } & \multicolumn{4}{|c|}{ Multivariate responses } & \multicolumn{7}{|c|}{ Univariate responses } \\
\hline & \multicolumn{3}{|c|}{ Wilks' } & \multirow[b]{2}{*}{$P$} & \multicolumn{3}{|c|}{ Large green frog } & \multicolumn{2}{|c|}{ Bullfrog } & \multicolumn{2}{|c|}{ Small green frog } \\
\hline & df & $\lambda$ & $F$ & & $\mathrm{df}$ & $F$ & $P$ & $F$ & $P$ & $F$ & $P$ \\
\hline$\overline{\text { Caged Anax (CA) }}$ & 231 & 0.61 & 10.0 & 0.0005 & 1 & 3.8 & 0.061 & 7.9 & 0.0086 & 14.24 & 0.0009 \\
\hline Small green frog & & & & & & & & & & & \\
\hline density (SG) & 231 & 0.15 & 83.0 & $<0.0001$ & 1 & 133.3 & $<0.0001$ & 113.8 & $<0.0001$ & 1125.5 & $<0.0001$ \\
\hline $\mathrm{SG} \times \mathrm{CA}$ & 231 & 0.78 & 4.34 & 0.012 & 1 & 7.0 & 0.013 & 5.9 & 0.021 & 6.6 & 0.017 \\
\hline Block (B) & 662 & 0.99 & 0.99 & 0.43 & 3 & 12.4 & 0.39 & 1.6 & 0.21 & 0.32 & 0.81 \\
\hline $\mathrm{CA} \times \mathrm{B}$ & 662 & 0.83 & 0.43 & 0.42 & 3 & 2.0 & 0.32 & 1.1 & 0.37 & 0.32 & 0.81 \\
\hline $\mathrm{SG} \times \mathrm{B}$ & 662 & 0.56 & 3.37 & 0.006 & 3 & 6.5 & 0.0014 & 1.7 & 0.20 & 0.09 & 0.96 \\
\hline $\mathrm{SG} \times \mathrm{CA} \times \mathrm{B}$ & 662 & 0.76 & 1.52 & 0.18 & 3 & 2.7 & 0.060 & 0.24 & 0.87 & 0.05 & 0.98 \\
\hline
\end{tabular}

Note: All mass gains were log transformed.

above the tank floor in the absence of caged Anax $(6 \%$ and $15 \%$, respectively) was greatly reduced by the presence of caged Anax (Fig. 4). Kruskal-Wallis tests showed no significant effect of small green frog density on the percent of small green frogs observed in the presence $(P=0.89)$ or absence $(P=0.16)$ of caged Anax. Small green frog density also did not have an effect on percent of bullfrog tadpoles above the tank floor in the absence of caged Anax (0.67), however the percent of small bullfrogs observed above the tank floor in the presence of caged Anax increased significantly with increases in small green frog density $(P=0.02)$.

\section{Laboratory experiment}

Caged Anax had a strong negative effect on the percent of small green frogs active and above the tank bottom (Fig. 5). Small green frogs were $\sim 24$ times less active and 54 times less apt to be above the tank bottom when in the presence of the caged Anax. In contrast, the caged Anax had no visible effect on the large green frog tadpoles. Caged Anax thus had a much weaker effect on large green frog behavior than on the small frog behavior. Note that, since the aquaria used in the laboratory experiment are much smaller than the cattle watering tanks, the chemical cue from the caged Anax is probably much stronger in the laboratory experiment. Thus the laboratory experiment may overestimate the effect of Anax on large green frog behavior, and our conclusion that large green frogs show little response to Anax is conservative.

\section{DISCUSSION}

\section{Support for the model predictions and proposed mechanisms}

The principal result of the cattle tank experiment was that the nonlethal effect of a predator on an assemblage of consumers was strongly dependent on the relative densities of the consumers. As predicted by the model, vulnerable and invulnerable competitor species were most strongly affected by the (caged) predator at different focal species densities. Specifically, caged Anax had a strong effect on individual small green frog $\left(C_{\mathrm{fs}}\right)$ mass gain at low small green frog density, but a negligible effect at high density (Prediction 1). Further, the indirect effect of caged Anax on competitors of the small green frogs changed as small green frog density increased. The positive effect of caged Anax on large green frog tadpole $\left(C_{1}\right)$ mass gain increased from $\sim 10 \%$ to $\sim 60 \%$ as small green frog density increased (Prediction 2). Finally, the strong negative effect of caged Anax on small bullfrog $\left(C_{2}\right)$ mass gain decreased from $\sim 40 \%$ to zero as small green frog density increased (Prediction 3 ).

We propose that the effects of the predator on mass gain of different species/size classes of this assemblage of consumers are a consequence of differential responses in activity level of the consumers. Evidence from past studies shows that the presence of Anax induces a reduction in activity level of small green frogs and bullfrogs (Werner 1991, Peacor and Werner 1997, Relyea and Werner 1999; Eklöv and Werner 2000). In the cattle tank experiment the number of small green frog tadpoles in the water column or on the tank sides greatly decreased in the presence of caged Anax at all small green frog densities. There was a similar response of small bullfrogs, however it was less strong at high green frog densities. We have previously shown that this shift in habitat use is associated with a decrease in foraging activity (Peacor and Werner 1997; P. Eklöv, unpublished data), as seen for the small green frogs in the laboratory experiment (Fig. 4). In contrast, the laboratory experiment indicated that the less vulnerable large green frog tadpoles react very little or not at all to caged Anax.

We suggest, as predicted by the model, that the behavioral responses of tadpoles to Anax resulted in counteracting effects on anuran growth: a negative direct effect mediated through activity reduction and a positive indirect effect mediated through reduced resource use by competitors (intraspecific and interspecific). The negative direct effect did not vary as a function of small green frog density, while the indirect positive effect 

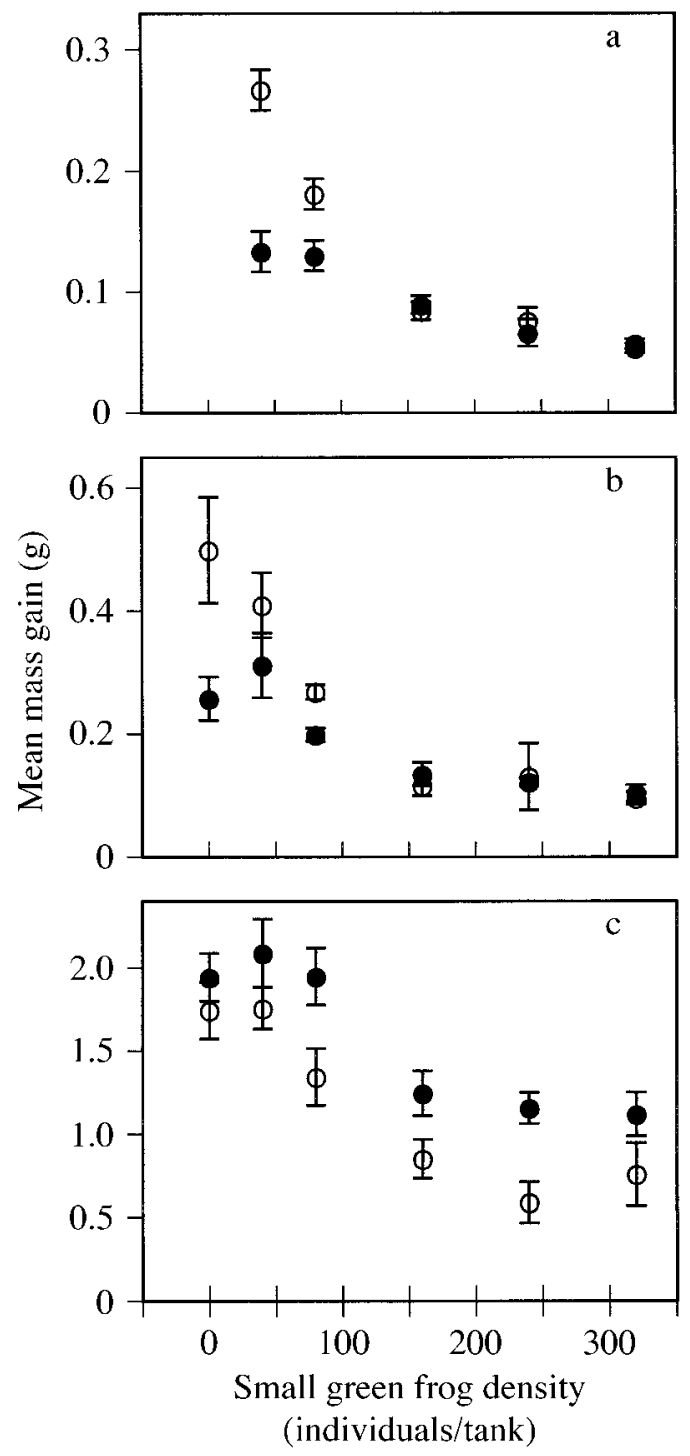

FIG. 3. Mean mass gain ( $\pm 1 \mathrm{SE}$ ) of (a) small green frogs, (b) bullfrogs, and (c) large green frogs as a function of initial small green frog density. Empty squares and filled squares represent treatments without and with the caged dragonfly predator Anax, respectively. Note different scales on $y$-axes.

increased as a function of small green frog density. Thus, for an individual consumer that reacted to the predator (a small green frog or small bullfrog), the negative effect of the predator dominated at low density, but was offset by the positive indirect effect of the predator at high small green frog density. For an individual consumer that did not react to the predator (a large green frog), there was no negative effect of the predator on growth rate, and thus there was no net effect on growth rate at low, but a positive indirect effect at high, small green frog density.

Model assumptions and alternative hypotheses

The model predictions were based on a number of simplifying assumptions. Most importantly, we as-

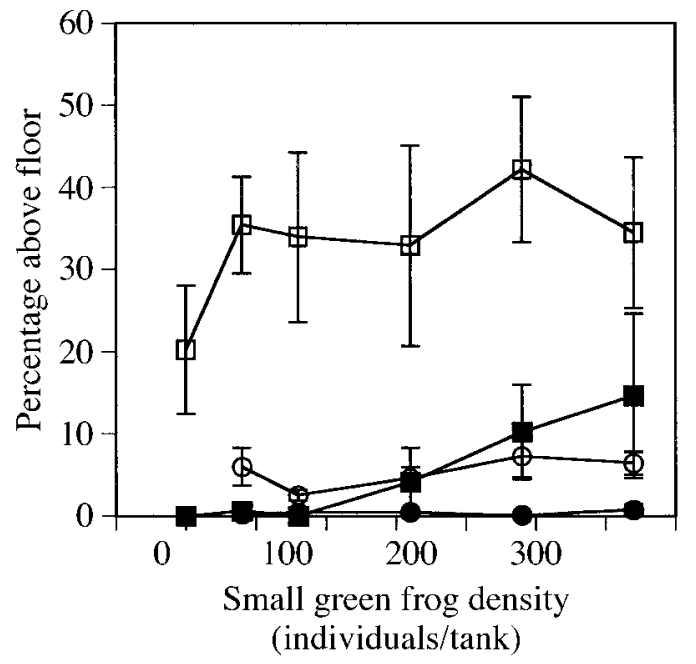

FIG. 4. Number (mean $\pm 1 \mathrm{SE}$ ) of small green frogs (circles) and bullfrogs (squares) observed above the cattle tank bottom in the presence (filled symbols) and absence (empty symbols) of caged Anax.

sumed that consumers forage randomly, acquire resources in direct proportion to resource density, and that consumer foraging rates did not depend on size. We assert, however, that relaxation of these assumptions does not alter the qualitative nature of the model predictions because they do not affect the two mechanisms responsible for the predicted patterns (the two counteracting effects discussed in the previous paragraph). For example, a simulation model relaxing the assumption of random foraging and including size dependent foraging produced qualitatively similar results (S. P. Peacor, unpublished data). Given the generality

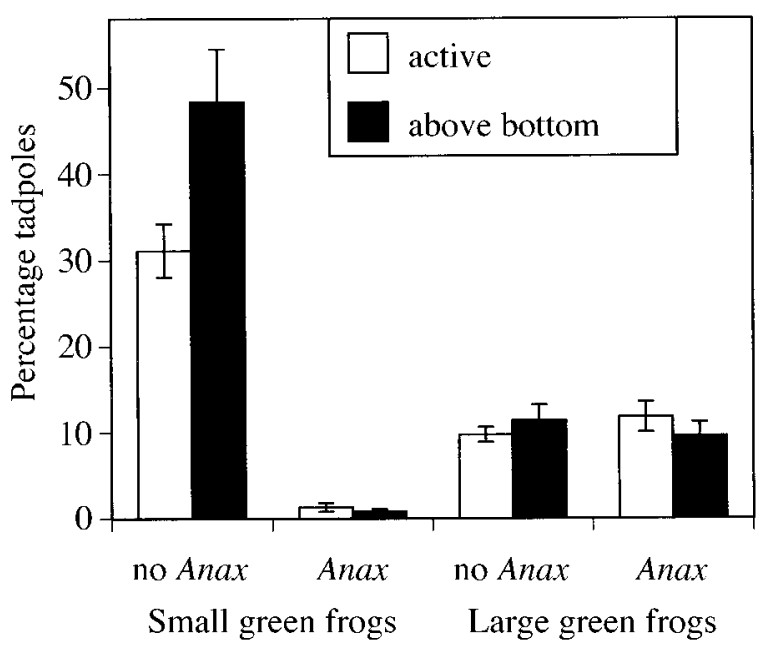

FIG. 5. Small and large green frog behavioral responses (mean $\pm 1 \mathrm{SE}$ ) to caged Anax in the laboratory experiment. The predator had a strong negative effect on the percentage of small tadpoles that were active (open bars), and percentage observed above the tank bottom (filled bars), but no effect on the behavior of large green frog tadpoles. 
of the basic mechanisms underlying the predictions of the model, we expect that these predictions will likely apply to a wide range of ecological systems.

Further, we did not consider resource dynamics. Our predictions are based on the fact that if the predator induces a reduction in focal species foraging effort a higher fraction of the resources will be available for consumption by competitors. It is possible, however, that resource productivity will increase under reduced foraging pressure. Thus competitors not only will be able to acquire a higher fraction of the resources in the presence of the predator, but the amount of resources available may increase enhancing the magnitude of the indirect effect of the predator. In fact, with sufficient increase in resource levels, the focal species $\left(C_{\mathrm{fs}}\right)$ actually may grow faster in the predator's presence (Abrams 1987); i.e., the increase in resource levels may more than compensate for the reduction in focal species foraging rate. This effect, however, is possible only at intermediate resource densities where a moderate reduction in foraging pressure can have a large positive effect on resource productivity. It therefore should have little effect at very low and high forager densities and hence does not alter our predictions. There is no direct evidence that this process contributed to our results.

We envision several alternative mechanisms that might lead to the observed interaction between caged predator presence and small green frog density. First, tadpole foraging and growth rate may increase with increased size, and hence any negative effect of the predator on growth rate will be magnified at high tadpole growth rates. The relative effects of the predatorinduced reduction in foraging activity on growth rates may then be greater at low density where tadpoles are larger due to increased growth rates. This mechanism, however, could not account for the absence of any effect of the predator on small green frog and small bullfrog mass gains at high small green frog densities. Further, this process would act to oppose the predicted and observed effect of the predator on large green frog mass gain. We thus discount this alternative hypothesis.

A second possible alternative explanation of our results is that the magnitude of the Anax-induced foraging reduction of small green frogs was dependent on small green frog density. In the model (Prediction section) the foraging reduction of the focal species was the same at all focal species densities (for simplicity of presentation). While our observations indicated that small green frog tadpoles reacted strongly to the predator at all small green frog tadpole densities, it is possible that more extensive observations would reveal a relationship between small tadpole density and the magnitude of the Anax-induced reduction in activity. We have observed that green frog tadpoles react less strongly to predators at very low resource levels (Peacor and Werner 1997). If the tadpoles reacted less strongly to the caged Anax at high tadpole densities, the effect of the predator on small green frog growth rates at higher densities would be weaker, and hence this could contribute to the patterns of mass gain we observed (Fig. 3). However, our observations showed a very strong negative effect of the predator on small green frog behavior at high density (Fig. 4). Thus, as in the first alternative hypothesis, this mechanism does not explain the absence of any effect on small green frog and small bullfrog growth at high small green frog densities. Furthermore, this mechanism cannot explain the increase in large green frog mass gain observed at high small green frog density.

Finally, a similar alternative mechanism could explain the small bullfrog results, because the relative effect of the predator on small bullfrog behavior was weaker at high small green frog densities (Fig. 4). This response could lead to the observed interaction between predator presence and small green frog density on bullfrog mass gain. We assert that this mechanism could not fully explain the results because there was no reduction in mass gain of small bull frogs even when there was a very large behavioral response of bullfrogs to the predator. (For example, see Figs. 3 and 4 at a small green frog density of 160). Thus, while a decrease in the behavioral response of the bullfrogs to the predator at high green frog density may have contributed to the decrease in the relative effect of the predator on bullfrog mass gain, it can not account for the large decrease observed.

\section{Relative magnitude of the indirect effects due to the predator through foraging and density reduction of the focal species}

Our data enable us to compare the magnitude of effects of the predator-induced foraging reduction relative to indirect effects that would result from predation, i.e., the trait-mediated indirect effect (TMII) relative to the density-mediated indirect effect (DMII). If we assume that the different densities of small green frog tadpoles in our experiment represent the consequences of different predation rates on hypothetical populations initialized at the same density, then a low or high prey density simulate high or low predation rate, respectively.

This comparison shows that the strength of the TMII of Anax on mass gain of large green frogs due to the foraging reduction of small green frogs is of the same order of magnitude as an indirect effect due to density reduction. For example, compare large green frog growth rates in the treatments with 240 small green frogs to the treatment with 80 small green frogs $(66 \%$ density reduction). When this comparison is made in the absence of caged Anax it isolates the effects due to density reduction from any effects due to induced foraging reduction of the predator. This comparison indicates that the small green frog density reduction led to a $\sim 50 \%$ increase in large green frog mass gain (Fig. 3c). Similarly, we can isolate the effects due to foraging reduction by comparing mass gain of large 
green frogs at a density of 240 small green frogs in the presence and absence of caged Anax. The caged presence of Anax resulted in a $\sim 50 \%$ increase in large green frog mass gain in this treatment. Thus the indirect effect of the predator on large green frogs through density and trait (foraging reduction) effects on small green frogs were of the same order of magnitude. Actual predation by Anax would reduce the small green frog density from 240 to 80 gradually over the course of the experiment. Thus any comparisons with indirect effects due to foraging reduction using the above method overestimates the relative magnitude of indirect effects due to density reduction, and yields a conservative estimate of the relative strength of effects due to foraging reduction. Thus these results suggest that TMIIs can be of similar magnitude as density-mediated indirect interactions.

\section{Implications of this study}

This investigation illustrates the value of examining individual traits to understand the mechanisms of community level processes. Based on individual behavioral responses, we predicted successfully how a predator affected other species in the food web as a function of the density of one intermediate species. Although the predictions we presented were qualitative, it should be possible to develop the functional relationships between species densities and species behavioral changes to make more quantitative predictions of these interactions.

In addition, we have shown that proximate responses (survival and growth rate) of an intermediate species in a food web do not adequately predict indirect interactions in the web. For example, one might expect that if a predator has little effect on the survival (via predation) and growth rate (via induced foraging reduction) of a prey species, that predators would have no consequences on competitors of the prey. However, in our experiment, a large positive TMII between caged Anax and large green frogs was observed when there was no observable effect of Anax on small green frogs. It is thus necessary to consider trait changes of prey explicitly to predict the consequences of a predator on a community.

The TMIIs resulting from the presence of the predator demonstrated in this investigation are based on a mechanism that is widespread in ecological communities. Many species from a range of taxa, both terrestrial and aquatic, can perceive changes in predation risk and adjust their behavior to reduce this risk (Lima 1998). Increasingly, investigators are demonstrating how these predator-induced changes in behavior of prey can indirectly affect other species in the food web (see references in Introduction). Though the majority of these studies are from aquatic systems, examples are beginning to emerge from terrestrial systems as well. For example, Schmitz and coworkers have shown that predator-induced changes in consumer activity and habitat use have large effects on resource levels in an old-field system composed of spiders, grasshoppers, and grasses and herbs (Schmitz et al. 1997, Schmitz 1998). Schmitz (1998) further shows that the indirect effects of spiders on resources are dominated by the induced changes in grasshopper behavior (the TMII), rather than that due to changes in grasshopper density (the density-mediated indirect interaction).

The model predictions investigated in this study depend on multiple prey species reacting differentially to predators. This is very likely the case for many competitor assemblages. Prey behavioral responses to predators should be correlated to risk (Sih 1987), and consumer risk is clearly dependent on size (as in our investigation), stage, palatability, and morphological defenses. Predator-induced changes in prey behavior may vary among prey for other reasons, such as differences in the ability of prey to detect predators. Thus we suggest that the types of nonlethal effects of a predator demonstrated in the simple aquatic food web of this study are general, and that the protocol that we present for predicting the consequences of the nonlethal effect of a predator on consumers may be useful in describing these effects in other communities.

In conclusion, we have shown how the magnitude of TMIIs may depend strongly on the relative densities of consumers, and that they may be of the same order of magnitude as indirect interactions caused by changes in prey density. Indeed, it is possible that many of the effects previously attributed to density-mediated indirect interactions are in fact due to TMIIs. At present there is a paucity of empirical and theoretical investigations examining the long-term implications of TMIIs to community dynamics and structure (but see Matsuda et. al 1993, Abrams 1995, McPeek and Peckarsky 1998, Vandermeer and Maruca 1998). The ubiquitous nature of the underlying mechanism of TMIIs (phenotypic plasticity), and their demonstrated impact on short term dynamics of food webs, suggests that their impact on population dynamics and community structure may be far reaching, and calls for further theoretical and empirical investigation.

\section{ACKNOWLEDGMENTS}

We wish to thank Alexandra Minn, Peter Eklöv, Karen Glennemeier, Beth McCollum, Rick Relyea, and Mara Zimmerman for assistance in conducting the experiments. We thank Josh VanBuskirk and George Kling for suggestions concerning nutrient addition. We thank James Gapczynski and Allan Sutton of the Michigan Department of Natural Resources for permission to collect, and help in collecting, bullfrog eggs from the Saline Pond Facility. Comments from Ian Billick, Peter Eklöv, Alexandra Minn, Barbara Peckarsky, Rick Relyea, Robert Rommel, Josh VanBuskirk, Kerry Yurewicz, Mara Zimmerman, and an anonymous reviewer greatly improved the manuscript. This work was supported by a University of Michigan Block Grant to S. D. Peacor and NSF grant DEB-9119948 to B. R. Anholt and E. E. Werner.

\section{Literature Cited}

Abrams, P. A. 1983. Arguments in favor of higher-order interactions. American Naturalist 121:887-891. 
Abrams, P. A. 1987. Indirect interactions between species that share a predator: varieties on a theme. Pages 38-54 in W. C. Kerfoot and A. Sih, editors. Predation: direct and indirect impacts on aquatic communities. University Press of New England, Hanover, New Hampshire, USA.

Abrams, P. A. 1993. Indirect effects arising from optimal foraging. Pages 255-279 in H. Kawanabe, J. E. Cohen, and $\mathrm{K}$. Iwasaki, editors. Mutualism and community organization: behavioral, theoretical and food web approaches. Oxford University Press, Oxford, UK.

Abrams, P. A. 1995. Implications of dynamically variable traits for identifying, classifying and measuring direct and indirect effects in ecological communities. American Naturalist 146: 112-134.

Abrams, P. A., B. A. Menge, G. G. Mittelbach, D. Spiller, and P. Yodzis. 1996. The role of indirect effects in food webs. Pages 371-395 in G. A. Polis and K. O. Winemiller, editors. Food webs: integration of patterns and dynamics. Chapman and Hall, New York, New York, USA.

Adler, F. R., and W. F. Morris. 1994. A general test for interaction modification. Ecology 75:1552-1559.

Beckerman, A. P., M. Uriarte, and O. J. Schmitz. 1997. Experimental evidence for a behavior-mediated trophic cascade in a terrestrial food chain. Proceedings of the National Academy of Sciences of the United States of America 94: $10735-10738$.

Billick, I., and T. J. Case. 1994. Higher order interactions in ecological communities: what are they and how can they be detected? Ecology 75:1529-1543.

Eklöv, P., and E. E. Werner. 2000. Multiple predator effects on size-dependent behavior and mortality in two anuran species. Oikos 88:250-258.

Huang, C. F., and A. Sih. 1990. Experimental studies on behaviorally mediated, indirect interactions through a shared predator. Ecology 71:1515-1522.

Kats, L. B., J. W. Petranka, and A. Sih. 1988. Antipredator defenses and the persistence of amphibian larvae with fishes. Ecology 69:1865-1870.

Kratz, K. W. 1996. Effects of stoneflies on local prey population: mechanisms of impact across prey density. Ecology 77:1573-1585.

Lawler, S. P. 1989. Behavioral responses to predators and predation risk in four species of larval anurans. Animal Behavior 38:1039-1047.

Lima, S. L. 1998. Nonlethal effects in the ecology of predator-prey interactions-what are the ecological effects of anti-predator decision-making? BioScience 48:25-34.

Lima, S. L., and L. M. Dill. 1990. Behavioral decisions made under the risk of predation: a review and prospectus. $\mathrm{Ca}-$ nadian Journal of Zoology 68:619-640.

Matsuda, H., P. A. Abrams, and M. Hori. 1993. The effect of adaptive anti-predator behavior on exploitative competition and mutualism between predators. Oikos 68:549559.

McCollum, S. A., and J. VanBuskirk. 1996. Costs and benefits of a predator-induced polyphenism in the gray treefrog Hyla chrysoscelis. Evolution 50:583-593.

McIntosh, A. R., and C. R. Townsend. 1996. Interactions between fish, grazing invertebrates and algae in a New Zealand stream: a trophic cascade mediated by fish induced changes to grazer behaviour? Oecologia 108:174-181.

McPeek, M. A., and B. L. Peckarsky. 1998. Life histories and the strengths of species interactions: combining mortality, growth, and fecundity effects. Ecology 79:867-879.

Menge, B. A. 1994. Indirect effects in marine rocky intertidal interaction webs: pattern and importance. Ecological Monographs 65:21-74.

Messina, F. J. 1981. Plant protection as a consequence of an ant-membracid mutulism: interactions on goldonrod (Solidago sp.). Ecology 62:1433-1440.
Miller, T. E., and W. C. Kerfoot. 1987. Redefining indirect effects. Pages 33-37 in W. C. Kerfoot and A. Sih, editors. Predation: direct and indirect impacts on aquatic communities. University Press of New England, Hanover, New Hampshire, US.

Neill, W. E. 1974. The community matrix and interdependence of the competition coefficients. American Naturalist 108:399-408.

Peacor, S. P., and E. E. Werner. 1997. Trait-mediated indirect interactions in a simple aquatic food web. Ecology 78: 1146-1156.

Polis, G. A., and K. O. Winemiller, 1996. Food webs: integration of patterns and dynamics. Chapman and Hall, New York, New York, USA.

Pomerantz, M. J. 1981. Do higher-order interactions in competition systems really exist? American Naturalist 117: 583-591.

Relyea, R. A., and E. E. Werner. 1999. Quantifying the relation between predator-induced behavioral responses and growth performance in larval anurans. Ecology 80:21172124.

Roughgarden, H., and J. Diamond. 1986. Overview: the role of species interactions in community ecology. Pages 333343 in J. Diamond and T. J. Case, editors. Community ecology. Harper and Row, New York, New York, USA.

Schmitz, O. J. 1998. Direct and indirect effects of predation and predation risk in old-field interaction webs. American Naturalist. 151:327-342.

Schmitz, O. J., A. P. Beckerman, and K. M. O’Brien. 1997. Behaviorally mediated trophic cascades: effects of predation risk on food web interactions. Ecology 78:1388-1399.

Schoener, T. W. 1993. On the relative importance of direct versus indirect effects in ecological communities. Pages 365-411 in H. Kawanabe, J. E. Cohen, and K. Iwasaki, editors. Mutualism and community organization: behavioral, theoretical and food web approaches. Oxford University Press, Oxford, UK.

Semlitsch, R. D. 1993. Effects of different predators on the survival and development of tadpoles from the hybridongenetic Rana esculenta complex. Oikos 67:40-46.

Sih, A. 1987. Predators and prey lifestyles: An evolutionary and ecological overview. Pages 203-224 in W. C. Kerfoot and A. Sih, editors. Predation: direct and indirect impacts on aquatic communities. University of New England Press, Hanover, New Hampshire, USA.

Skelly, D. K. 1995. A behavioral tradeoff and its consequences for the distribution of Pseudacris treefrog larvae. Ecology 76:150-164.

Skelly, D. K., and E. E. Werner. 1990. Behavioral and life historical responses of larval american toads to an odonate predator. Ecology 71:2313-2322.

Smith, D. C., and J. VanBuskirk. 1995. Phenotypic design, plasticity, and ecological performance in two tadpole species. American Naturalist 145:211-233.

Soluk, D. A. 1993. Multiple predator effects: predicting combined functional response of stream fish and invertebrate predators. Ecology 74:219-225.

Soluk, D. A., and N. C. Collins. 1988. Synergistic interactions between fish and stoneflies: facilitation and interference among stream predators. Oikos 52:94-100.

Turner, A. T., and Mittelbach, G. G. 1990. Predation avoidance and community structure: interactions among piscivores, planktivores and plankton. Ecology 71:2241-2254.

Vandermeer, J. H. 1969. The competitive structure of communities: an experimental approach with Protozoa. Ecology 50:362-372.

Vandermeer, J. 1981. A further note on community models. American Naturalist 117:379-380.

Vandermeer, J., and S. Maruca. 1998. Indirect effects with a 
keystone predator: coexistence and chaos. Theoretical Population Biology 54:38-43.

Werner, E. E. 1991. Nonlethal effects of a predator on competitive interactions between two anuran larvae. Ecology 72:1709-1720.

Werner, E. E. 1992. Individual behavior and higher-order species interactions. American Naturalist 140:S5-S32.

Werner, E. E., and B. R. Anholt. 1996. Predator-induced behavioral indirect effects: consequences to competitive interactions in anuran larvae. Ecology 77:157-169.

Wilbur, H. M., and J. E. Fauth. 1990. Experimental aquatic foodwebs: interactions between two predators and two prey. American Naturalist 135:176-204.
Wissinger, S., and J. McGrady. 1993. Intraguild predation and competition between larval dragonflies: direct and indirect effects of shared prey. Ecology 74:207-218.

Wootton, J. T. 1993. Indirect effects and habitat use in an intertidal community: interaction chains and interaction modifications. American Naturalist 141:71-98.

Wootton, J. T. 1994. Putting the pieces together: testing the independence of interactions among organisms. Ecology 75:1544-1551.

Wootton, J. T. 1997. Estimates and tests of per capita interaction strength: diet, abundance, and impact of intertidally foraging birds. Ecological Monographs 67:45-64. 